\title{
The time and place for appropriate radionuclide imaging: Now and everywhere
}

\author{
Robert C. Hendel, MD, FASNC, FACC, FAHA, ${ }^{a}$ \\ and Gregory S. Thomas, MD, MPH, FASNC, FACC ${ }^{b}$
}

See related article, pp. 1044-1052

The economics of health care have been a serious source of concern in the United States for the past several decades. Spiraling health care costs and reported profiteering by physicians have garnered increasing public attention. However, it is notable that growth of medical imaging has received much of the notoriety. ${ }^{1,2}$

Although concerns related to increased use of imaging are not unique to the United States, the high US volume of procedures such as SPECT myocardial perfusion imaging has created a rather provincial response which is firmly rooted in our domestic system of payment for non-Medicare patients. Private third party payers have initiated progressively more onerous utilization strategies, including the ever-increasing use of radiology benefits managers (RBM's). ${ }^{3}$ One of the main limitations of RBM utilization management has been their independent creation of "guidelines" determining reimbursement for specific tests and indications. These "guidelines" frequently lack a basis in the medical literature and developed predominately without input from physician specialty and subspecialty societies. The American College of Cardiology (ACC) and American Society of Nuclear Cardiology (ASNC), in addition to other societies, responded to this vacuum with the development of Appropriate Use Criteria (AUC) in $2005,{ }^{4}$ and with an updated version in $2009 .{ }^{5}$ The goal of AUC was to provide clinicians, payers, and patients

From the Cardiovascular Division, ${ }^{\mathrm{a}}$ University of Miami Miller School of Medicine Miami, Miami, FL; and Mission Internal Medical Group, ${ }^{\mathrm{b}}$ University of California, Irvine, Mission Viejo, CA.

Reprint requests: Robert C. Hendel, MD, FASNC, FACC, FAHA, Cardiovascular Division, University of Miami Miller School of Medicine, 1123 NW 14 Street, CRB 1120, Miami, FL 33133; rhendel@med.miami.edu.

J Nucl Cardiol 2011;18:997-9.

$1071-3581 / \$ 34.00$

Copyright $@ 2011$ American Society of Nuclear Cardiology.

doi:10.1007/s12350-011-9439-z with guidance towards the rational/reasonable use of cardiac imaging, providing an evidence based alternative to RBM policies.

Patient safety in imaging is of primary importance, providing the impetus to reduce radiation exposure and improve dosimetry. ${ }^{6}$ The technical efforts from the cardiac imaging community to reduce radiation exposure are laudable. However, this approach begins with the determination of whether the procedure itself should be performed. As such, the AUC promotes the concept that the right patient undergoes radionuclide imaging only when potential benefits exceed risks. This is not only a national priority, being a key component of patient-centered imaging, but a worldwide goal.

The current paper by Gholamrezanezhad et $\mathrm{al}^{7}$ demonstrates an international extension of AUC. Limited data are presently available for non-US evaluation of appropriateness of the use of AUC, ${ }^{8}$ although findings have now been reported for Canada, England, Sweden, and Germany. This current effort in Iran represents the first application of AUC in a developing country. However, more than geography is in play. The basic structure of AUC is based on risk assessment, that is dependent on the risk model selected (e.g., ATP III, Reynold's score), each of which was developed for a US population. Other countries, however, may have a markedly different disease prevalence based largely on differences in risk factor prevalence, ethnicity, and access to preventive cardiology care. Each of these risk factors alters the use and value of this risk model. This is supported by a younger population in the current study when compared with other assessments of appropriateness. ${ }^{9,10}$

Three sets of appropriateness determinations were performed in this study: (1) a local panel used their own clinical judgment to categorize the appropriateness of each case, (2) panel assignment according to specific 2005 AUC indications, and (3) panel assignment according to specific 2009 AUC indications. Overall, the authors report levels of appropriateness similar to that found by others (Table 1). The authors unique method to define appropriate testing by a panel of local experts is potentially problematic. First, the rigorous process for the determination of appropriate use emphasized within each of the ACCF AUC documents is based on analysis 
Table 1. Peer reviewed publications regarding utilization of radionuclide myocardial perfusion imaging, based on appropriate use criteria

\begin{tabular}{lccc}
\hline & Appropriate (\%) & Uncertain (\%) & Inappropriate (\%) \\
\hline Mehta $^{10}$ & 80 & 7 & 13 \\
Gibbons et al $^{17}$ & 64 & 11 & 14 \\
Hendel et al $^{9}$ & 71 & 15 & 14 \\
Gibbons et al $^{12}$ & 66 & 15 & 7 \\
Carryer et al $^{11}$ & 60 & 16 & 24 \\
Koh et al $^{8 *}$ & 82 & 5 & 10 \\
Gupta et al $^{18 *}$ & 84 & 5 & 11 \\
Gholamrezanezhad et al $^{7 *}$ & 75 & 5 & 17 \\
\hline
\end{tabular}

* 2009 ACCF/ASNC/ACR/AHA/ASE/SCCT/SCMR/SNM appropriate use criteria.

of the literature would be expected to be more robust and consistent than local expert opinion. As well, the use of such an expert opinion panel does not ensure consistency with other guidance documents, especially clinical practice guidelines. The large number of uncertain categorizations by the local panel underscores the value of the more objective AUC. The authors point out the AUC often do not take into account specific and unique features of each individual case; this apparent loss in flexibility is offset, in our opinion, by a more objective and standardized approach to the assessment of appropriate utilization.

One of the most important aspects of this paper is the comparison of the 2005 and 2009 ACCF/ASNC/ ACR/AHA/ASE/SCCT/SCMR/SNM AUC. The authors found that use of the revised AUC reduced the frequency of cases not able to be classified and that good agreement was noted between the two sets of AUC (2005, 2009), with a concordance of $80 \%$ and a Kappa value of 0.63 . A significant increase in inappropriate designations (11.0\% to 16.8\%) between 2005 and 2009 was observed. One of the few other contributions that compared the 2009 to the 2005 AUC also found an increase in the inappropriate rate. ${ }^{11}$ However, in contrast to this report by Carryer, ${ }^{11}$ Gholamrezanezhad et al did not find a complete elimination of the unclassified category, although, only $2.7 \%$ of studies fell into this category. This is similar to the findings of Koh et al. ${ }^{8}$

This current paper acknowledges the lack of awareness of appropriate use criteria by Iranian health care providers. While US practitioners, especially cardiologists, may be aware of the AUC, knowledge of the concept is far from universal, especially among noncardiologists. It is in this latter group of physicians where the highest percentage of inappropriate studies originates. ${ }^{7,9,10}$ In the other recent international study of appropriate use, Koh et al also applied the 2009 AUC.
They appear to have studied a unique cohort, as pre-op evaluation was the most common inappropriate indication (59\%). Gholamrezanezhad et al and most studies, ${ }^{7,9,10}$ found SPECT imaging in low risk patients (either asymptomatic or those with an interpretable ECG and who are able to exercise) as the major causes for testing which is classified as inappropriate.

With the recognition that inappropriate RNI is a worldwide concern, how can we improve utilization? Inherently there is a hope, as the authors point out, that clinicians can reduce inappropriate studies. However, traditional educational methods in isolation are unlikely to improve patterns of use., ${ }^{9,13}$ A multifaceted approach, including interactive learning and methods to provide feedback to the individual healthcare provider, would be most likely to be effective. One such approach has been the ACC's FOCUS project (http://www.cardiosource.org/ FOCUS) featuring decision support, a tool to objectively evaluate levels of appropriateness juxtaposed with a learning community to exchange ideas. Preliminary results have shown a reduction of $55 \%$ inappropriate testing, ${ }^{14} \mathrm{far}$ beyond the goal set at the White House Summit on Health Care in $2009 .{ }^{15} \mathrm{~A}$ recent paper on the ability to bend the cost curve notes the publication of AUC as a component in the slowing of growth of imaging in the US, as well as crediting the cardiology community for its accomplishment of managing growth of nuclear cardiology testing through its use. ${ }^{16}$

Throughout the world, emphasis continues to be placed on a patient-centered approach to care. The appropriate use of radionuclide imaging is consistent with this vision. Along with the potential economic impact garnered from the reduction of inappropriate testing and the preservation of patient access to warranted imaging studies, continued promulgation of AUC seems crucial to the global survival of nuclear cardiology and is simply the "right thing to do". 


\section{References}

1. Inglehart JK. Health insurers and medical-imaging policy-A work in progress. N Engl J Med 2009;360:1030-7.

2. Medicare Payment Advisory Commission (PedPAC). Report to congress: improving incentives in the medicare program; 2009. http://www.medpac.gov/documents/Jun09_EntireReport.pdf. Accessed 18 July 2011.

3. Hendel RC. Utilization management of cardiovascular imaging: Pre-certification and appropriateness. J Am Coll Cardiol Imaging 2008;1:241-8.

4. Brindis RG, Douglas PS, Hendel RC, Peterson ED, Wolk MJ, Allen JM, et al. ACCF/ASNC appropriateness criteria for singlephoton emission computed tomography myocardial perfusion imaging (SPECT MPI): A report of the American College of Cardiology Foundation Strategic Direction Committee Appropriateness Criteria Working Group and the American Society of Nuclear Cardiology. J Am Coll Cardiol 2005;46:1587-605.

5. Hendel RC, Berman DS, Di Carli MF, Heidenreich PA, Henkin RE, Pellikka PA, et al. ACCF/ASNC/ACR/AHA/ASE/SCCT/ SCMR/SNM 2009 Appropriate Use Criteria for cardiac radionuclide imaging. A report of the American College of Cardiology Foundation Appropriate Use Criteria Task Force, the American Society of Nuclear Cardiology, the American College of Radiology, the American Heart Association, the American Society of Echocardiography, the Society of Cardiovascular Computed Tomography, the Society for Cardiovascular Magnetic Resonance, and the Society of Nuclear Medicine. J Am Coll Cardiol 2009;53: 2201-29.

6. Cerqueira MD, Allman KC, Ficaro EP, Hansen CL, Nichols KJ, Thompson RC, et al. Recommendations for reducing radiation exposure in myocardial perfusion imaging. J Nucl Cardiol 2010;17:709-18.

7. Gholamrezanezhad A, Shirafkan A, Mirpour S, Rayatnavaz M, Alborzi A, Mogharrabi M, et al. Appropriateness of referrals for single-photon emission computed tomography myocardial perfusion imaging (SPECT-MPI) in a developing country: A comparison between 2005 and 2009 versions of ACCF/ASNC appropriateness criteria. J Nucl Cardiol. doi:10.1007/s12350-011-9419-3.

8. Koh AS, Florse JL, Keng FY, Tan RS, Chua TS. Evaluation of the American College of Cardiology Foundation/American Society of Nuclear Cardiology appropriateness criteria for SPECT myocardial perfusion imaging in an Asian tertiary cardiac center. J Nucl Cardiol 2011;18:324-30.
9. Hendel RC, Cerqueira M, Douglas PS, Caruth KC, Allen JM, Jensen NC, et al. A multicenter assessment of the use of singlephoton emission computed tomography myocardial perfusion imaging with appropriateness criteria. J Am Coll Cardiol 2010;55: $156-62$.

10. Mehta R, Ward RP, Chandra S, Agarwal R, Williams KA. Evaluation of the American College of Cardiology Foundation/ American Society of Nuclear Cardiology appropriateness criteria for SPECT myocardial perfusion imaging. J Nucl Cardiol 2008; 15 : $337-44$.

11. Carryer DJ, Hodge D, Miller TD, Askew JW, Gibbons RJ. Applications of appropriateness criteria to stress single-photon emission computed tomography sestamibi studies: A comparison of the 2009 revised appropriateness criteria to the 2005 original criteria. Am Heart J 2010;160:244-9.

12. Gibbons RJ, Askew JW, Hodge D, Miller TD. Temporal trends in compliance with appropriateness criteria for stress single-photon emission computed tomography sestamibi studies in an academic medical center. Am Heart J 2010;159:484.

13. Gibbons RJ, Askew JW, Hodge D, Kaping B, Carryer DJ, Miller TD. Appropriate use criteria for stress single-photon emission computed tomography sestamibi studies: A quality improvement project. Circulation 2011;123:499-503.

14. Taylor A, Saifi S, Allen J, Hendel R. National initiative to improve utilization of cardiac imaging: The FOCUS learning community and performance improvement module. Washington: AHA QCOR Poster Session; 2011.

15. http://www.cardiosource.org/News-Media/Media-Center/NewsReleases/2009/03/5.aspx?w_nav=Search\&WT.oss=White $\% 20$ House\%20imaging\%20summit\&WT.oss_r=6\&.

16. Levin DC, Rao VM. Bending the curve: The recent marked slowdown in growth of noninvasive diagnostic imaging. AJR Am J Roentgenol 2011;196:W25-9.

17. Gibbons RJ, Miller TD, Hodge D, Urban L, Araoz PA, Pelikka P, et al. Application of appropriateness criteria to stress single-photon emission computed tomography sestamibi studies and stress echocardiograms in an academic medical center. J Am Coll Cardiol 2008;51:1283-9.

18. Gupta A, Tsiaras SV, Dunsiger SI, Tilkemeier PL. Gender disparity and the appropriateness of myocardial perfusion imaging. J Nucl Cardiol 2011;18:588-94. 